\title{
"I have Felt so Much Joy": The Role of Emotions in Community Sponsorship of Refugees
}

\author{
Jenny Phillimore $^{1}$ (i) $\cdot$ Marisol Reyes-Soto $^{1} \cdot$ Gabriella D'Avino $^{1} \cdot$ Natasha Nicholls $^{1}$
}

Accepted: 24 March 2021 / Published online: 12 April 2021

(C) The Author(s) 2021

\begin{abstract}
Resettlement programmes are considered one solution to displacement following the so-called refugee crisis. Private or community-based sponsorship models enable volunteer groups to take responsibility resettling refugees. The UK Community Sponsorship scheme (CS) allows volunteer groups to support refugee families in their community. This paper explores the role of emotions in CS using Jaspers three-stage social action life cycle (1998) drawing upon Doidge and Sandri's (Br J Sociol 70: 463-480, 2018) positive and negative emotions, Jaspers (Sociol Forum 13: 397-424, 1998) reactive and affective continuum and Hoggett and Miller's (Community Dev J 35: $352-364,2000$ ) individual/group features to explore the role of emotions in CS work. Using interview data collected from 123 interviews with 22 sponsorship groups, we find across the life cycle that there is a shift from negative reactive emotions during group initiation to positive affective emotions during consolidation and finally a mix of negative and positive affective emotions as groups become sustained. Understanding the role of emotions in motivating and sustaining volunteers is essential to the success of the CS, to encourage group formation and reduce burnout.
\end{abstract}

Keywords Volunteers · Emotions · Refugees · Community sponsorship - Social action

Jenny Phillimore

j.a.phillimore@bham.ac.uk

1 School of Social Policy, Sociology and Criminology, Institute for Research Into Superdiversity, University of Birmingham, Edgbaston, Birmingham B15 2TT, UK

\section{Introduction}

The question of how to encourage refugee resettlement into the Global North has replaced the talk of a refugee crisis which dominated in 2015-2016 (Guild et al., 2015; Holmes \& Castañeda, 2016). The conceptualisation of these events as a "crisis" has been criticised given the inadequate response of many of the wealthier states who coined the expression (Pace \& Severance, 2016). Unprecedented arrivals within parts of Europe but more importantly in countries bordering Syria, and media coverage showing the plight of children, for a short time captured the attention of ordinary people, many who demanded Government action. The scaling up of resettlement programmes has been a major outcome of public pressure. According to the United Nations High Commissioner for Refugees (UNHCR), ${ }^{1}$ in 2016 despite the level of forced displacement reaching its highest since records began with 65.6 million people forcibly displaced by 2017 , only 189,300 were resettled. Since the "crisis", much effort has been placed on promoting refugee resettlement with UNHCR, the European Commission, and other Government and humanitarian actors seeking resettlement pledges from wealthier nations.

Despite criticism that resettlement programmes create a distinction between good and bad refugees (Szczepanik, 2016), resettlement has been widely embraced by religious and civil society groups who have supported the development of welcome groups and promoted resettlement to communities with little experience of refugees. Community or private sponsorship of refugees has been increasingly supported in the Global North. Following the success of the

\footnotetext{
${ }^{1}$ See: Global Trends Forced Displacement in 2016, UNHCR available in https://www.unhcr.org/globaltrends2016/, retrieved on $12 / 02 / 2020$.
} 
Canadian model, the Global Refugee Sponsorship Initiative (GRSI) was introduced to "help countries create opportunities for their citizens to participate directly in the humanitarian effort to support the world's refugees via community-based sponsorship programs" (GRSI, 2019). The UK was the second country to establish a Community Sponsorship Scheme (CS) and has been followed by programmes in ten countries including New Zealand, Germany and Ireland with others such as Japan contemplating the approach. Yet little is known about the nature and functioning of these new resettlement programmes. If we are to increasingly depend on communities to support resettled refugees, we need to know how their actions are motivated and sustained through the emotions they experience. This paper examines the ways that emotions shape the actions of CS volunteers as they move from group establishment to consolidation. Adopting the social action life cycle approach proposed by Jasper (1998) and bringing together ideas around reactive/affective, positive and negative and collective and individual emotions, the paper is the first of its kind to examine the role of emotions in CS and contributes to the literature on volunteering and refugee befriending.

\section{Community Sponsorship}

CS was introduced in 2016 by the Home Office, the UK Government department responsible for immigration. The scheme was part of the Vulnerable Person Resettlement Programme (VPRS) intended to settle 20,000 refugees in the UK by 2020. Development of the scheme was influenced by the Canadian Private Sponsorship model, wherein civil society groups sign agreements committing to support refugees within their communities. The Canadian programme has resettled more than 300,000 refugees since 1972 (Bond \& Kwadrans, 2019). The UK Government was attracted to the idea of community groups taking responsibility for welcoming, assisting and settling vulnerable refugee families believing it to be an effective way to support integration.

Since 2016 around 150 CS groups have been established (Sponsor Refugees, 2019) and almost 400 refugees have been resettled (Home Office, 2019). To form a group, organisations must have some formal constitution or be associated with a charity, raise $£ 9000$ per household, identify suitable housing, obtain local authority consent, develop a safeguarding policy, engage in training and complete an extensive application form. Groups are supported by the charity Reset Communities and Refugees (Reset), established by the Government to support CS groups. The UK model has attracted much attention worldwide.
CS is described by the UK's Home Office as " $a$ way that community groups can be involved in supporting the resettlement of vulnerable people fleeing conflict". The underpinning idea is that extensive support offered by local people offers ready-made social capital that can accelerate refugee integration processes. Unlike the Canadian scheme, UK volunteers cannot sponsor "named" refugees; thus, the assistance they give in time is entirely directed at strangers selected by the United Nations High Commission for Refugees (UNHCR). Despite the growing importance of resettlement across the globe and the heightened interest in sponsorship models, little is known about the role of emotions in motivating volunteers to offer support to refugee strangers.

Civil action is at the heart of CS with groups being established by activists and then depending upon the contribution of volunteers to support a refugee family. Thus engagement in CS might be considered a combination of social protest and prosocial behaviour. Support is functional, social and cultural yet underpinned by humanitarian principles. Volunteers' relationships with refugees could also be conceived as a form of befriending involving forming an emotionally connected relationship with potential to aid inclusion and cohesion (Balaam, 2015) with relationships mediated by an overseeing organisation, the CS group. In CS, the "lead sponsor" (the charity) is key to establishing boundaries. Without a strong lead, interactions and emotional involvement permitted depend exclusively on volunteers who may not have sufficient experience and knowledge in establishing appropriate boundaries. Behnia (2007) finds that refugee organisations struggle to recruit and retain volunteers. Generally, they rely on a middleaged professional woman demographic for whom involvement often ceases when they lose motivation. Understanding the nature and role of emotions in generating action and attracting and retaining volunteers is essential to the success of sponsorship type programmes as they are increasingly introduced across the Global North.

\section{Emotions and Civil Society Activity}

Emotions have been described as the glue of solidarity and the mobiliser of conflict (Collins, 1990). They are important to consider for groups and individuals as they can make or break civil society action. Hoggett and Miller (2000) identified three important features of emotions for individual and groups. Firstly, emotions are an integral part of individual's lives. Secondly, collective ways of feeling such as humanitarian sentiments are often shared. Thirdly, emotional cultures can be present at micro-social level, where feelings belong to the social network. Groups are fundamentally emotional; emotions bring individuals 
together and emotions are themselves shaped by the participation in, and through, the creation of new networks. The relationship between groups and emotions lead Hoggett and Miller (2000) to argue that emotions, "if harnessed sensitively, provide the basis for creative collective action" (p360). Doidge and Sandri (2018) go further to argue that emotions are so core to mobilisation and maintenance of social action that voluntary groups would not exist without them.

But how are emotions integral to civic action such as the formation of, or participation in, a CS group? Emotions are associated with moral values, they can arise when moral rules are considered broken (Jasper, 1998). Actions undertaken collectively intensify emotions experienced by individuals legitimising and reinforcing their appropriateness (Doidge \& Sandri, 2018). Doidge and Sandri (2018) argue that positive and negative moral emotions are connected to political responses. Positive moral feelings, such as compassion, concern and sympathy, attract people towards the subject of their emotion and might encourage individuals to form or participate in CS. Feelings of compassion about the plight of refugees could result in individuals wishing to offer support. Alternatively, negative moral emotions such as guilt, embarrassment or shame push people away from the subject preventing their participation. Karakayali (2017) finds that both positive and negative emotions contribute to the forging of social connections between individuals and collectives, looking to Scheff (1994) and Goffman (1963) who show that shame and pride were core to collective action. Turning to the prosocial behaviour literature scholars tend to focus on binaries in relation to engagement around social issues with emphasis on whether volunteers are motivated by pleasure or pressure (i.e. Gebauer et al. 2008) such as guilt and outrage (Thomas et al., 2009), selfishness or altruism (Penner, 2004).

Jasper (1998) focuses on affective and reactive emotions seeing them as at either end of a continuum and key to social protest. Reactive responses can be temporary reactive and evoked in relation to an event or action and, following Doidge and Sandri (2018), could be negative reactive for example where outrage prompts action. Alternatively, responses within a social movement can be permanent affective reactions in the form of love and loyalty: positive affective emotions that bind groups together. Positive affective responses could be strong enough for people to seek-out or establish a CS group while negative or reactive emotions could result in individuals leaving (Jasper, 1998).

Social action results from the interaction between negative and positive affects, benevolence and altruism (Louis et al., 2019) and reactions at individual and collective levels. Reactions are likely to prompt action and affects likely to sustain it. Jasper (1998) identifies three phases in the life cycle of social movements that might be applied to CS groups. The first refers to emotions that generate initial responses leading to the initiation of action. The second is a consolidation phase where emotions contribute to group establishment. The third phase considers the longer-term sustainability of the group. In the following section, we explore the role of positive and negative, reactive and affective emotions across the life cycle setting out a framework for understanding the role of emotions in motivating CS activity.

\section{Generating Action}

Moral shocks and a sense of outrage can prompt people to take action, join a movement or engage in prosocial behaviour (Thomas et al., 2009). Positive or negative affects are connected to moral sensibilities expressed through emotion when objects of affection are threatened. For negative emotional reactions to prompt action, there needs to be someone to blame. Jasper (1998) identifies causal and remedial forms of blame focusing on those considered to cause the problem or with responsibility for fixing it. Threats to individuals' moral self-image can also generate prosocial actions (White \& Peloza, 2009). To move beyond outrage participants need to align their frames through developing a common idea about how they can solve their social problem. A frame is "an interpretative schema simplifying the world" (Snow and Benford, 1986, 137 in Jasper, 1998). Motivational dimensions of framing are under-researched in social actions, but it appears that the injustice frame is particularly important. Threat, outrage and anger are powerful negative emotional motivators for initial action aimed at something unjust (Jasper, 1998; Thomas et al., 2009). Jasper considers the role of emotion in group formation. Shared interests and identification with shared beliefs or principles such as faith/ religion can be important. Fundamentally, collective identity is about positive affect towards other group members making participation pleasurable and offering a sense of pride (Polletta \& Jasper, 2001). Social sharing of emotion has been found to create links between people subsequently generating prosocial actions (Peters \& Kashima, 2007).

Scholars examining the motivations of volunteers working with asylum seekers and refugees find emotions have a key role in prompting actions. Volunteers at the Calais refugee camps (known as "the Jungle") became engaged after the moral shock of Alan Kurdi's death (Sandri, 2018). Doidge and Sandri (2018) highlight the importance of empathy as individuals viewed actions against refugees as a personal attack leading them to share refugees' distress. They took action to alleviate their 
distress resulting in empowerment by using social action to generate positive emotions. In Germany, Lantos et al. (2020) identified the importance of pity, a negative affective emotion, in generating prosocial behaviour on behalf of refugees. Other work suggests positive affective responses in the form of a shared sense of responsibility to others based on a desire to help (Askins, 2014; Stock, 2017) or a sense of moral responsibility to alleviate suffering (Jędrzejowska-Schiffauer \& Schiffauer, 2017). Clearly, emotions are key in prompting individuals to act for refugees, and thus, both negative reactive and positive affective emotions may contribute to CS group formation.

\section{Consolidation of Actions}

According to Loftland, maintenance of group membership depends on the development of a "rich social movement culture" (Jasper, 1998, 416). Jasper argues components of this culture have an emotional side "entailing joy, hope, enthusiasm, pride and affective attachment to the group" (p416). Certainly, prosocial behaviour scholars identify a key role for pleasure in motivating individuals to volunteer with shared emotions important in group activity (Swaab et al., 2007). These positive affective emotions may be enough to sustain action when the group's goals are not met. Reciprocal emotions, in the form of feelings towards each other, and shared emotions, enable cohesiveness after the initial sense of outrage passes. Additionally, the opportunity to articulate moral principles offers pride and fulfilment within an appropriate frame.

Positive affective emotions attracting individuals to others are under-researched in voluntarism (Doidge \& Sandri, 2018). Although the role of trust in maintaining social networks has received attention, love and devotion has attracted little interest as have emotions such as hope, and happiness. Doidge and Sandri (2018 highlight joy and shared sense of purpose in fostering conviviality and emotional gratification. Malkki (2015) reflecting on volunteering in Greek refugee camps notes that time spent on a shared purpose quickly leads to affective outcomes.

Positive feelings in the form of emotional bonds between volunteers support the continuance of actions originating from negative emotions. Karakayali (2017), Askins (2014) and Atkinson (2018) find positive emotions develop with refugees who were eventually described as "family" portrayed as "like us". While refugee/volunteer relations can be understood as an imbalance of power with refugees often conceptualised as passive and needy (Akrap, 2015; Darling, 2011), these relations can evolve. In some cases, bonds become equal and reciprocal, the affects that tie people together strengthen, thereby consolidating the action (Askins, 2014). CS groups have collective responsibility to a refugee family for a minimum of two years ${ }^{2}$ during which time retaining volunteers is essential. The development of positive affective emotions is essential to ensure continuance.

\section{Sustaining Social Action}

There have been few studies of the decline of social action groups. Jasper sees risks of cessation associated with frustration, breakdown of relationships and emotional burnout. CS commitments to a sponsored family are considered most successful when relations continue past two years and/or via repeat sponsorship. For these aspirations to be met, groups must be sustained, and volunteers retained.

Okun and Kim (2016) demonstrate that while moral pressure may stimulate prosocial action generally volunteering is sustained by pleasure. Emotional labour offers the greatest risk to volunteers' continued participation. Hochschild (2012) describes the risks associated with commercialising and routinising feelings where emotional management is expected through managing feelings and the conflict between what is felt and what is expressed results in psychological strain. Little consideration has been given to the role of emotional labour in refugee work and how volunteers manage emotions.

Doidge and Sandri (2018) find collective emotional work necessary to support others experiencing strong feelings when volunteering with refugees. Emotional labour can involve positive and negative emotions. Askins (2014) finds volunteers experienced their own emotional distress when hearing refugees' stories. Affective emotions of love and concern were triggered, but volunteers felt unable to display anguish for fear of causing upset to others. Negative emotions may also require emotional labour. Karakayali (2017), Maestri and Monforte (2020) and Atkinson (2018) describe how volunteers found refugee behaviours frustrating but felt they should hide their feelings. They managed negative emotions by focusing on practical tasks, notions of shared humanity or by offering explanations for behaviours. Feeling different to the emotion being expressed can lead to exhaustion and burnout. Taylor et al. (2007) show how volunteers can experience emotional burnout when tasks are badly distributed, expectations are unclear or there are intra-organisation disagreements. Simsa (2017) researching volunteer responses to the arrival of refugees in Austria in 2015 found that overwork and lack of training generated burnout. There is a strong risk that individuals, in an unpaid capacity, might quit if burned out. Without a volunteer base, CS is unsustainable so it is important to explore the

\footnotetext{
$\overline{2}$ Although at present the average time it takes to move from formation to receiving a family is in excess of 2 years (Reset personal communication February 2020).
} 
emergence of problematic emotions to understand how to support volunteers to remain.

\section{Methods}

The data utilised herein comes from an independent study designed to inform the development of the UK's CS scheme. The study ran between 2017 and 2020 and explored refugee and volunteer experiences from pre-group formation to 12 months after refugee arrival. This paper uses data from interviews with 123 volunteers from 22 groups. Having received full ethical approval from the University of Birmingham Ethical Review Committee, we used a purposive sampling approach to identify groups. We sought a mix of faith-based and secular groups with twelve faith-orientated and ten secular. We identified groups across different types of area from eight in multicultural urban areas, six in less diverse suburbs and eight in places with little experience of diversity. We interviewed 22 group leaders whose ages ranged between 50 and 70s, and four to six volunteers in each group. The gender of interviewees, 109 women and 36 men, corresponded to that of CS volunteers generally (three quarters women), 141 were white-British and 110 retired or semi-retired. Respondents were in between their $30 \mathrm{~s}$ and $80 \mathrm{~s}$ with $78 \%$ over 60 years of age. Groups ranged in size from between 8 and 15 volunteers including leaders. Eight groups were interviewed before they had resettled a family; the remainder were interviewed after the family arrived. All refugees were resettled from Syria, Jordan, Lebanon, Turkey or Iraq.

After receiving permission from the UK Government, we worked with Reset to access a list of CS groups from which we selected a range of secular/non-secular groups located in diverse and less diverse areas across each of the UK's four countries who were then approached by Reset and invited to participate. Groups that agreed were sent a participant information form detailing the aims and objectives of the study alongside a discussion of data storage, confidentiality and data usage. They were asked to identify a range of volunteers who worked with them. They invited their entire volunteer body for interview and shared information and consent forms with those who came forward. Our interviewer (Author 2) then contacted volunteers directly and arranged a face to face interview. Relying on volunteers to self-select risked only those with a particular story to tell coming forward. We did, however, garner a range of views. Our interviews included questions about feelings, motivations and experiences from getting involved in $\mathrm{CS}$ in the first instance to the current time. Clearly, we were dependent on the selective memories of respondents. It is possible that they had experiences which they either could not, or did not want to, recall. We were unable to interview volunteers who had left the group although volunteer attrition was discussed with group leaders.

Data were coded using a systematic thematic analysis approach (Guest et al., 2012) to identify the key issues raised. This involved interpretive code-and-retrieve methods wherein the data were read by the research team who together identified codes and then undertook an interpretative thematic analysis. The quotations used in this paper were selected on the basis of their ability to illustrate those issues.

\section{Findings}

The critical role of emotions in CS is summed up by the following female, urban, faith group volunteer who imply that emotions alone are sufficient to prompt and sustain social action "You don't need to be well supported if the people who come are the ones who are really passionate about it". In this section we explore the role of emotions across the social action life cycle.

\section{Initiating Action}

CS action tended to be initiated following negative reactive emotions experienced by individuals who felt compelled to act and in this respect supported on the pressure more than the pleasure argument for prosocial behaviour (Penner, 2004). The image of Alan Kurdi, the Syrian toddler washed up on a beach, was particularly influential for CS volunteers with children or grandchildren who reported experiencing outrage and empathy.

At our first meeting I had a 3-month-old and I brought her to the meeting as I was still breastfeeding. Seeing some of the images of what was going on, I felt like I had to do something, I feel like I've not done enough! Female, rural, secular volunteer

Seeing these images prompted women in particular to meet with friends to discuss what they could do or to attend a meeting organised by others. Volunteers spoke of feeling helpless and upset. Attending or organising a meeting offered a way of feeling they were doing something and as Doidge and Sandri (2018) show in relation to volunteering in Calais helps to assuage some of the distress they felt.

The sense of doing something and not just watching stuff on the news, and thinking, 'oh dear isn't that appalling, isn't that dreadful.' Female, rural, secular volunteer

Whilst images promoted outrage, volunteers also expressed negative reactive emotions in the form of blame. 
As they watched events unfold on television and the often highly emotive responses of volunteer helpers in mainland Europe, they realised that action was possible, and the British Government was not stepping up. The lack of an appropriate response was met with anger and indignation with the expectation that the Government had responsibility for a remedial response yet failed to deliver. Initiating community action at local level was a way of pushing back and demonstrating what was possible.

Campaigning for refugees in general came from a deep indignation on how the British government responds to the crisis.... I thought before I get really bitter and frustrated about how different the approach is, I thought I'd try and do something more proactive, and that's how I joined the policy campaign Female, urban, faith group volunteer

More positive reactive emotions were described by more than half of volunteers who saw the unfolding crisis as an opportunity to make a difference. Individuals focused on the pleasures they would derive from helping others in need and of being part of something bigger indicating that pleasure too had a role in promoting prosocial action (Gebauer et al., 2008). In that respect joining and contributing to a group was experienced positively, connecting community with the possibility of reciprocal relations.

Without diminishing that this is about refugee protection first and foremost, it is a really valuable community thing Male, urban, secular volunteer

As Jasper (1998) suggests, aligning with particular moral frames whether spiritual or other belief systems was also part of individuals' motivation to join a CS group. CS offered an opportunity for frame alignment through providing a common approach whereby people could seek to address the emergency faced by refugees. As with other forms of social action the injustice frame was important

Social Justice... I have always been involved in social justice; it is part of my life Female, suburban, faith group volunteer

But humanitarianism was also raised

I suppose I like the humanitarian side of the CS. And it was a way that I felt yes I could do it Male, suburban, faith group volunteer

Faith groups have been closely involved with CS as both the Pope and the head of the Church of England called for action and church leaders across the UK responded. Congregations came together at the behest of a local faith leader. Shared belief and the opportunity to practice their faith through action was a major motivator as was positive moral self-image (Abeywickrama et al., 2018).
"Halfway through I felt like I have done something in my life that is by God and I thought if I can do something that counts, I will do this" Female, urban, faith group volunteer

\section{Consolidating Action}

After the initial spur to action, groups began to consolidate with a shift from reactive individual emotions to positive affective emotions and the emergence of a collective identity aiding membership maintenance as pleasure began to be more important than pressure. Shared beliefs in the group as an entity were important in helping them to develop a collective identity that helped motivate them to forge forwards despite multiple struggles associated with a frustrating and highly bureaucratic and rapidly evolving application process. Small successes in the face of challenges improved group morale and bound them together.

There were various highs, various lows ... we'd almost lost interest because it wasn't going anywhere! About 6 months ago [when housing was approved], it really started to feel as though some-

thing was coming together, the group was coming

together and that's when we said: 'let's keep going

Female, rural, secular volunteer

Perhaps most important as groups consolidated were the reciprocal relations developed between group members. A small number of volunteers talked about feeling lonely or isolated before getting involved; others referred to their experiences recovering from illnesses or bereavement. Being part of a CS group extended friendship circles. Positive affective emotions between volunteers generated a sense of collective responsibility towards the group and the refugee family. It also brought positive improvements to the lives of individual volunteers helping to bind volunteers to each other and the group.

"I love the likeminded group of friends in this team"

Female, urban, secular volunteer.

"I gained friendship, I gained a family" Female, suburban, faith group volunteer.

Initially, affective emotions developed between volunteers and were crucial in getting them through the long application process. If approval was received, the highlight for groups was the arrival of the family. Not all volunteers worked closely with the family and not all developed relationships with them, working in other roles. Over time reciprocal relations developed between refugee family members and some individual volunteers, particularly volunteer interpreters. Most volunteers felt responsibility for the family and indeed the term "our" family was 
invoked which might imply some degree of patronage or ownership, or affection.

"A family wasn't a family anymore, it was our family” Female, urban, faith volunteer.

Individual volunteers developed interpersonal relationships with refugees, most often a woman volunteer with a refugee woman and began to refer to them as "extended family".

We want to be the extended family for these refugees. That's how we want to appear, that we really are there for them as fellow human beings.... We want to make them feel at home in our society. This is our home, come in, you are welcome Female, suburban, secular volunteer

The two families' relationships gradually intertwined across generations, volunteers reported feeling love and devotion and experiencing mutual affection based on a common humanity. These relationships were described as meaningful and important, improving the quality of the volunteers' lives and generating pleasure.

It was clear that for many that being part of the group brought joy and sociability. Enjoyment and happiness were frequently invoked as being part of the volunteer experience. These positive emotions lie somewhere between affect and reaction and emerged from gratification derived from actions they were engaged in, from being part of something and from making a difference.

\section{"We burst into tears, goose bumps everywhere. Two years of hard work seemed to pale into insignifi- cance... it actually has been full of twists and turns and sometimes we'd not known what was round the corner. To see their faces... was just like the most perfect Christmas gift" Female, suburban, faith group volunteer}

Pleasure was gained through empowerment.

"I cannot even begin to tell you what I have gained...so much...so much, joy, the feeling of having a purpose, the feeling of changing something ...the power of little people" Female, suburban, faith volunteer

Volunteers spoke of the collective pride they experienced in their achievement, an emotion that bound them together and motivated them to do more reinforcing Goffman's (1963) argument about the centrality of pride to collective action.

"I am very proud of us, I'm sure we'll be successful" Male, urban, secular volunteer.

\section{Sustaining Action}

With the frustrations of the application process behind them and the initial joy of receiving "their" family passing, the "real work" was said to begin as volunteers worked closely with the refugees and authorities on integration. This period was intense and stressful, few groups realised how difficult it would be to work with people who spoke no English with no awareness of local systems and culture. Refugees were often overwhelmed, and volunteers worried about them. Volunteers reported working more hours than anticipated. Tensions sometimes emerged within the group as they struggled to agree on a course of action for the family. Should they push for attendance at language classes when a refugee man was clearly struggling? Should they drive a refugee woman and her child to hospital, or should she be expected to get there independently? The role played by the group leaders became critical as they sought to manage negative emotions and maintain group cohesion.

"When your team has people with strong personalities you need a lot of patience. My role as a group leader is to try to help people to work with each other. I was the negotiator or mediator in moments of big tension and frustration" Female, suburban, faith volunteer

But tensions could also lead to individuals leaving.

"It was a big fall out because the leader of the group actually left the group" Male, suburban, faith group volunteer

A small number of volunteers became frustrated with the refugee adults they supported. CS often involves bringing volunteers together who have no experience of working with refugees. They are expected to support the family to independence within a year, but have no knowledge of the reality of refugee integration challenges wherein learning English and getting work can take years (Phillimore \& Goodson, 2006). Sometimes, expectations did not match reality and frustrations emerged with some blame apportioned onto the refugees rather than the Government for failing to establish realistic expectations.

"They don't have motivation. I am quite conflicted because they need to try harder. It is an awful thing to say, because I know that they lost everything",

Female, rural, secular volunteer

There were clear signs of burnout in some groups, and we were told by three group leaders about a tendency for some volunteers to quit after several months. Volunteers felt overwhelmed as it became clear that a year would not be enough for refugees to attain financial independence, experiencing what might be described as a negative 
affective emotion, a sense of obligation that undermined the pleasure Okun and Kim (2016) indicate is so important to sustain prosocial behaviour.

"At times we felt like in the same way that with an extended family you can feel oppressive, sometimes, all of us we felt that they have leaning on us too much, honestly" Male, urban, secular volunteer "Many members of the group are exhausted. We are very fond of them-family-but we cannot see an end of this" Female, urban, secular volunteer

It was evident that volunteers would express their discontent with each other but not with refugees. They engaged in emotional labour to pursue the group's goals continuing with their work and not directly questioning refugee actions despite disagreeing with them and, or telling refugee families that they were themselves feeling tired and overwhelmed.

"I feel uncertainty of where it goes... and we will be there for them but like our children we may not like the choices that they make, but we will be there as a group with the family, but where it goes, very difficult to know..." Male, suburban, secular volunteer

Despite frustrations and tensions between volunteers and volunteers and refugees, many groups sustained and many volunteers were retained. Several groups have sponsored a second family and two groups a third. Throughout the CS life cycle, the majority of individuals reported finding great satisfaction in their CS work resulting from positive emotions: affective bonds with others and the refugee family, a sense of purpose and pride, with joy and sociability consolidating and even intensifying despite the hard work indicating the importance of pleasure in long-term sustainability of CS actions. These responses combined both individual and collective emotions.

\section{"It has been very enriching, but it has been much harder work than we anticipated, but much more rewarding and I've gained very good friends and neighbours, people I am very fond of. It has been very nice” Female, urban, faith group volunteer}

\section{Discussion}

Following the so-called refugee crisis, humanitarian organisations are increasingly looking to resettlement programmes to meet the needs of the world's refugees. Yet there is currently a shortfall of 1.2 million resettlement places (UNHCR, 2019). Much hope has been placed on Community and Private Sponsorship as means to meet the shortfall with the UK as the first CS scheme outside of Canada seen as an important example of what is possible. GRSI is promoting sponsorship in the hope that replicating the success of the Canadian model in other Western countries will address the shortfall. While CS schemes are developing, the extent to which communities are engaging with CS is not growing as quickly as hoped with some groups failing before receiving a family or not continuing beyond a single family. Understanding the role of emotions in the CS life cycle can help the development of policy and practice which might better support the growth of CS schemes.

It is evident as Jasper (1998) shows in relation to social action that some form of reactive emotion experienced by individuals has largely been the driver of CS in the UK. The media coverage of the "crisis" and the distress and empathy felt by individuals, especially women, who then organised friends, family and community, was a key motivator. In prosocial behaviour terms, pressure was in the first instance a key driver for action (Penner, 2004). As the media furore around the "crisis" recedes the original drivers of outrage are less evident. Indeed, the presence of a CS scheme in itself means that individuals are less likely to be motivated by remedial blame (Jasper, 1998) as the moral responsibility for action passes from Government to communities whose job it is to take up the mantle and establish a group. We might argue that as such, the injustice frame, one of the key motivators of individual action (Jasper, 1998), becomes less important.

The promise of making a difference and of "doing community" through CS offered another motivation for CS volunteers building on the prospect of pleasure (Gebauer et al., 2008) and positive rather than negative reactive emotions. The prospect of making a difference offers scope for motivating future groups, particularly if the emotional positives of CS can be optimised and shared through word of mouth. Indeed, a positive emotional approach is now adopted in roadshows across the UK and in GRSI marketing, wherein experienced volunteers expound the joys of CS to potential sponsors. The spiritual frame emerged as being of great importance in motivating action which is unsurprising given the involvement of churches in the establishment of CS. Faith is likely to continue to be an important frame as faith leaders push for action and individuals see $\mathrm{CS}$ as a way of practising their faith. There are indications too that other faith groups are becoming more involved with the number of Jewish and Muslim-led, as well as interfaith initiatives, increasing.

Once groups are established, positive affective emotions become more important; indeed, as Collins (1990) has shown they become the social glue binding groups together. Shared emotions (Peters \& Kashima, 2007) emerge as individuals build relationships and establish common 
goals. But these can be accompanied by individual reciprocal relationships developing between some volunteers and refugees (Askins, 2014) as volunteers felt refugee affection towards them. Such reciprocity has been shown to be a key dimension of new migrant integration (Phillimore et al., 2018) and benefits volunteers in increasing their pleasure and sense of belonging while empowering refugees. Most volunteers interviewed talked of the positive affective emotions that resulted from CS involvement which included expanding friendship circles, depth of friendships, a sense of purpose and of place. Some reported feeling greater affection for their community more generally. These positive emotions are key to group consolidation and, as Doidge and Sandri (2018) have shown, convert a bunch of like-minded people into a group with purpose and, as Okun and Kim (2016) show, sustains prosocial behaviour more generally. The sense of responsibility they feel for each other and their goal enables them to persevere despite multiple disappointments and setbacks. That some groups do not make it to the stage of receiving a family may relate to an inability to consolidate perhaps resulting from the absence of sufficiently strong affective bonds and thus group identity, lack of leadership with managing expectations and emotions, or insufficient progress to be able to develop a sense of pride. The time taken to submit an application may also be a factor as it can be difficult to sustain positive emotions in the face of extensive bureaucracy. Further research is needed with "failed" groups to explore the reasons why they felt unable to proceed.

CS is relatively new in the UK and has been developing slowly in the four years since it was introduced so few groups have reached the latter stages of Jasper's (1998) life cycle. We are however able to identify some of the key threats to sustainability as well as the opportunities. Over time negative affective emotions are more likely to emerge. Group work can be difficult, and tensions arise especially around disagreements on approaches to refugee support some of which are morally framed around differing ideas of patronage and independence. The liking of refugee/group relations to that of a family was extremely common with refugees portrayed as the children and volunteers having expectations of progress and actions that were not always met. The emotional labour of caring for refugees, being worried about their future, with expectations and an unrealistic timeframe for independence put groups under pressure and could lead to burnout. Volunteers, in describing their frustrations and the way they managed them in order to avoid expressing their feelings, indicated that emotional labour was an expected, if unspoken part of CS work. In our discussions with group leaders around volunteer retention and support it was evident that burnout was only considered in relation to time and not feelings. Yet CS work, like befriending, depends heavily on codified social relations (Balaam, 2015), and mechanisms are needed to help volunteers to experience their emotions without the dissonance that Hochschild (2012) has shown to be problematic. This may make the experience of volunteering more pleasurable and aid retention.

While some volunteers talked of exhaustion and expressed largely negative emotions, many more spoke of hard work accompanied by a growth in positive emotions: affective as a group, with other volunteers and refugees, and reactive as pride in the achievements of the group and of the refugees. Given the core importance of volunteers to $\mathrm{CS}$, practical measures are needed in order to maximise positive feelings and minimise negatives. Such actions are likely to include managing expectations, ensuring sufficient volunteers are recruited, strong leadership charged with monitoring volunteer well-being and encouraging feedback about problems and pleasures, the introduction of a crossgroup self-help discussion forum for CS volunteers and peer mentoring within and across groups. Further research is needed to examine in more detail the factors which shape volunteer experiences as the sponsorship movement expands across the globe. Such research might consider group dynamics and structure and personalities as well as the role of emotions.

\section{Conclusions}

This paper has explored the role of emotions in CS using across Jasper's (1998) social action life cycle and demonstrated that emotions have a key role in the initiation, consolidation and sustainability of CS action. Drawing together Jasper's affective/reactive continuum, Hoggett and Miller's (2000) individual/group features, Doidge and Sandri (2018) typology of positive and negative human emotions and the pressure/pleasure prosocial behaviour binary, we show how over the life cycle there is a shift from largely negative reactive emotions or pressure motivations to positive affective and then potentially negative affective but also intensified positive emotions and pleasure motivations. We demonstrate the importance of injustice and faith frames in generating reactions and show the potential for the often-overlooked joy and sociability (Doidge \& Sandri, 2018) and pride (Goffman, 1963) in sustaining action. While our approach offers a useful way to understand the cycle of emotions, our frame should be viewed as a heuristic devise because it portrays emotions as static when they are intrinsically dynamic, unpredictable, unstructured and subjective.

Since the UK introduced its CS scheme, a further ten programmes have been developed across the world with a further ten under development (GRSI personal 
communication 9/11/20). All rely heavily on the engagement of communities to support volunteers with both time and finance. Given the importance placed on growing communities to help address the Global North resettlement deficit, it is important that we understand the role of emotions in motivating volunteers to initiate and sustain such social action. If CS is to grow globally, there is a need to provide individuals with a strong rationale for action. Promoting the potential of CS to enable the development of positive emotions and pleasure, alongside the inevitable hard work, may provide a useful motivator in the absence of the moral outrages and remedial blame motivators. Further maximising the potential for positive affective and reactive emotions by providing groups with appropriate support and realistic expectations may reduce negative reactions and emotional burnout and aid the sustainability of CS.

Funding This study was funded by the University of Birmingham (internal funds).

\section{Declarations}

Conflict of interest The authors declare that they have no conflict of interest.

Ethical Approval This project received full ethical approval from the University of Birmingham Ethical Review Committee approval number ERN_17-1508.

Open Access This article is licensed under a Creative Commons Attribution 4.0 International License, which permits use, sharing, adaptation, distribution and reproduction in any medium or format, as long as you give appropriate credit to the original author(s) and the source, provide a link to the Creative Commons licence, and indicate if changes were made. The images or other third party material in this article are included in the article's Creative Commons licence, unless indicated otherwise in a credit line to the material. If material is not included in the article's Creative Commons licence and your intended use is not permitted by statutory regulation or exceeds the permitted use, you will need to obtain permission directly from the copyright holder. To view a copy of this licence, visit http://creativecommons. org/licenses/by/4.0/.

\section{References}

Abeywickrama, R., Laham, S., \& Crone, D. (2018). Immigration and receiving communities: The utility of threats and emotions in predicting action tendencies toward refugees, Asylum-Seekers and economic migrants. Journal of Social Issues, 74(4), 756-773.

Akrap, D. (2015). Germany's response to the refugee crisis is admirable. But I fear it cannot last. The Guardian. [online] Available at: https://www.theguardian.com/commentisfree/ 2015/sep/06/germany-refugee-crisis-syrian [Accessed 27 Feb. 2020].

Askins, K. (2014). A quiet politics of being together: Miriam and Rose. Area, 46(4), 353-354.
Atkinson, M. (2018). Refugee mentoring: Sharing the journey. Peace and Conflict: Journal of Peace Psychology, 24(3), 338-342.

Balaam, M. C. (2015). A concept analysis of befriending. Journal of Advanced Nursing, 71(1), 24-34.

Behnia, B. (2007). An exploratory study of befriending programs with refugees: The perspective of volunteer organizations. Journal of Immigrant and Refugee Studies, 5(3), 1-19.

Bond, J., \& Kwadrans, A. (2019). Resettling refugees through community sponsorship: A revolutionary operational approach built on traditional legal infrastructure. Refuge, 35(2), 86-108.

Collins, R. (1990). Conflict theory and the advance of macrohistorical sociology. In J. Ritzer (Ed.), Frontiers of social theory: The new syntheses. Columbia University Press.

Darling, J. (2011). Giving space: care, generosity and belonging in a UK Asylum drop-in centre. Geoforum, 42(4), 408-417.

Doidge, M., \& Sandri, E. (2018). 'Friends that last a lifetime': The importance of emotions amongst volunteers working with refugees in Calais. The British Journal of Sociology, 70(2), 463-480.

Gebauer, J. E., Riketta, M., Broemer, P., \& Maio, G. R. (2008). Pleasure and pressure based prosocial motivation: Divergent relations to subjective well-being. Journal of Research in Personality, 42, 399-420.

Goffman, E. (1963). Stigma. Penguin.

GRSI (2020). Personal Zoom conversation between Jenny Phillimore and GRSI in Canada and Europe (Took place 9th November 2020).

Guest, G., MacQueen, K. M., \& Namey, E. E. (2012). Applied thematic analysis. (pp. 3-20). Sage Publications.

Guild, E., Costello, C., Garlick, M., \& Moreno-Lax, V. (2015). The 2015 refugee crisis in the European Union. (pp. 4-9). CEPS Policy Brief, CEPS.

Hochschild, A. R. (2012). The managed heart: Commercialization of human feeling. . University of California Press.

Hoggett, P., \& Miller, C. (2000). Working with emotions in community organizations. Community Development Journal, 35(4), 352-364.

Holmes, S. M., \& Castañeda, H. (2016). Representing the "European refugee crisis" in Germany and beyond: Deservingness and difference, life and death. American Ethnologist, 43(1), 12-24.

Global Refugee Sponsorship Initiative. (2019). Guidebook and Planning Tools Based on Canada's Model [online] Available at: http://refugeesponsorship.org/guidebook [Accessed 27 Feb. 2020].

Jasper, J. M. (1998). The emotions of protest: Affective and reactive emotions in and around social movements. Sociological Forum, 13(3), 397-424.

Jędrzejowska-Schiffauer, I., \& Schiffauer, P. (2017). New constraints on mobility in Europe: Policy response to European crises or constitutional ambiguity? Journal of International Studies, 10(3), 9-23.

Karakayali, S. (2017). Feeling the scope of solidarity: The role of emotions for volunteers supporting refugees in Germany. Social Inclusion, 5(3), 7-16.

Lantos, N. A., Kende, A., Becker, J. C., McGarty, C., (2020). Pity for economically disadvantaged groups motivates donation and ally collective action intentions. European Journal of Social Psychology, 50(7), 1478-1499. https://doi.org/10.1002/ejsp.2705.

Louis, W. R., Thomas, E., Chapman, C. M., Achia, T., Wibisono, S., Mirnajafi, Z., \& Droogendyk, L. (2019). Emerging research on intergroup prosociality: Group members' charitable giving, positive contact, allyship, and solidarity with others. Social and Personality Psychology Compass, 13(3), 1-16.

Maestri, G., \& Monforte, P. (2020). Who deserves compassion? The moral and emotional dilemmas of volunteering in the 'refugee crisis.' Sociology, 54(5), 920-935. 
Malkki, L. H. (2015). The need to help: The domestic arts of international Humanitarianism. . Duke University Press.

Home Office (2019). How many people do we grant asylum or protection to?. Immigration statistics, year ending June 2019 second edition, National Statistics. [online] Available at: https:// www.gov.uk/government/publications/immigration-statisticsyear-ending-june-2019/how-many-people-do-we-grant-asylumor-protection-to [Accessed 27 Feb. 2020].

Okun, M. A., \& Kim, G. Y. (2016). The interplay of frequency of volunteering and prosocial motivation on purpose in life in emerging adults. The Journal of Social Psychology, 156, 328-333.

Pace, P., \& Severance, K. (2016). Migration terminology matters. Forced Migration Review, 51, 69-70.

Penner, L. A. (2004). Volunteerism and social problems: making things better or worse? Journal of Social Issues, 60, 645-666.

Peters, K., \& Kashima, Y. (2007). From social talk to social action: Shaping the social triad with emotion sharing. Journal of Personality and Social Psychology, 93(5), 780-797.

Phillimore, J., \& Goodson, L. (2006). Problem or opportunity? Asylum Seekers, refugees, employment and social exclusion in deprived Urban Areas. Urban Studies, 43, 1715-1736.

Phillimore, J., Humphris, R., \& Khan, K. (2018). Reciprocity for new migrant integration: Resource conservation, investment and exchange. Journal of Ethnic and Migration Studies, 44(2), 215-232.

Polletta, F., \& Jasper, J. M. (2001). Collective identity and social movements. Annual Review of Sociology, 27(1), 283-305.

Sponsor Refugees. (2019). What is community sponsorship?. [online] Available at: https://www.sponsorrefugees.org/what_it_is [Accessed 24 Dec. 2019].

Sandri, E. (2018). 'Volunteer Humanitarianism': Volunteers and humanitarian aid in the Jungle refugee camp of Calais. Journal of Ethnic and Migration Studies, 44(1), 65-80.

Scheff, T. J. (1994). Bloody revenge: Emotions, Nationalism, and War. . Westview Press.
Simsa, R. (2017). Leaving emergency management in the Refugee Crisis to Civil Society? The Case of Austria. Journal of Applied Security Research, 12(1), 78-95.

Snow, D. A., Rochford, E. B., Jr., Worden, S. K., \& Benford, R. D. (1986). Frame alignment processes, micromobilization, and movement participation. American Sociological Review, 51(4), 464-481.

Stock, I., (2017). Daring to care? How volunteers and civil society organisations are shaping asylum seekers' access to citizenship through social support. Working Papers-Centre on Migration, Citizenship and Development, 156.

Swaab, R., Postmes, T., van Beest, I., \& Spears, R. (2007). Shared cognition as a product of, and precursor to, shared identity in negotiations. Personality and Social Psychology Bulletin, 33(2), 187-199.

Szczepanik, M. (2016). The "Good" and "Bad" Refugees? Imagined Refugeehood (s) in the media coverage of the migration crisis. Journal of Identity and Migration Studies, 10(2), 23-33.

Taylor, T., Mallinson, C., \& Bloch, K. (2007). "Looking for a Few Good Women": Volunteerism as an interaction in two organizations. Nonprofit and Voluntary Sector Quarterly, 37(3), 389-410.

Thomas, E. F., McGarty, C., \& Mavor, K. I. (2009). Transforming "apathy into movement": The role of prosocial emotions in motivating action for social change. Personality and Social Psychology Review, 13, 310-333.

UNHCR (2019). Less than 5 per cent of global refugee resettlement needs met last year. [online] Available at: https://www.unhcr. org/uk/news/briefing/2019/2/5c6bc9704/5-cent-global-refugeeresettlement-needs-met-year.html [Accessed 27 Feb. 2020].

White, K., \& Peloza, J. (2009). Self-benefit versus other-benefit marketing appeals: Their effectiveness in generating charitable support. Journal of Marketing, 73(4), 109-124.

Publisher's Note Springer Nature remains neutral with regard to jurisdictional claims in published maps and institutional affiliations. 